\title{
Circulating immune complexes and rheumatoid arthritis: a comparison of different assay methods and their early predictive value for disease activity and outcome
}

\author{
J S REEBACK, ${ }^{1}$ A J SILMAN ${ }^{2}$ E J HOLBOROW,${ }^{1}$ R N MAINI, ${ }^{3}$ AND \\ F C $\mathrm{HA} \mathrm{Y}^{4}$
}

From the ${ }^{1}$ Bone and Joint Research Unit and ${ }^{2}$ Epidemiology Department, London Hospital Medical College, ${ }^{3}$ Kennedy Institute of Rheumatology, and ${ }^{4}$ Department of Immunology, Middlesex Hospital Medical School

SUMmARY The performance of four different assays for circulating immune complexes-the Clq solid phase method, one using protein $A$ and one using anti-IgG, C1q PEG, and the $2 \%$ PEG method-were compared in 61 patients with early rheumatoid arthritis followed up for two years. There were weak but statistically significant correlations between the results from some of the pairs of assays, but the changes over time from any single assay did not correlate with those from any of the other assays. None of the assays predicted either future disease activity, as measured by subsequent ESR, CRP, and articular index; or functional outcome, as measured by wrist extension, Steinbocker functional capacity, and the Stanford health assessment questionnaire. It is unlikely therefore that the measurement of immune complexes is of value in predicting early outcome in patients with rheumatoid arthritis.

Key words: rheumatoid arthritis diagnosis, rheumatoid arthritis natural history.

Circulating immune complexes (CIC) have been shown to be present in both the blood ${ }^{1}$ and synovial fluid $^{2}$ of patients with rheumatoid arthritis (RA). These observations have suggested a possible pathogenic role of CIC in RA, in particular for the development of extra-articular manifestations of the disease. ${ }^{3-5}$ It is thus of interest to evaluate whether the measurement of CIC at an early stage in the course of RA might be useful as a predictor of outcome. There are, however, many different available methods of measuring CIC in sera, the majority of which involve complement fixation. These different methods may not all measure the same material, and therefore they might have different prognostic values. In the WHO study ${ }^{6}$ the 18 different available assays differed in the ability to discriminate between RA and disease-free sera.

In this report the results from four different assays for CIC on patients with early RA are

Accepted for publication 11 July 1984 .

Correspondence to Dr J Reeback, Department of Rheumatology, Edgware General Hospital, Edgware, Middlesex. presented with regard to the interassay variation within patients, including change in assay results over time, and the possible predictive power of CIC assays in determining future disease activity and severity.

\section{Patients and methods}

PATIENTS

The entry criteria were patients with classical or definite rheumatoid arthritis ${ }^{7}$ who were within 18 months of first onset of symptoms. The three participating centres were encouraged to enter all appropriate patients aged 18 or over presenting in a 12-month period. In all, 81 patients were entered and assessed by a single observer (J.R.). Five were subsequently excluded, as the original diagnosis of classical or definite RA proved erroneous, and a further four were lost to follow-up. The 72 remaining patients, 24 males and 48 females, had a mean age of first symptoms of 49.6 years (median 51, range $22-71$ ). The mean delay between symptom 
onset and entry to the study was 11 months (median 12 months, range 3-18 months).

\section{CLINICAL ASSESSMENT}

This was carried out by a single observer (J.R.) and included the Ritchie articular index (AI), ${ }^{8}$ Steinbocker functional capacity (FC), ${ }^{9}$ Stanford health assessment questionnaire (HAQ), ${ }^{10}$ and visual assessment of wrist extension. The latter permitted allocation of the patients to one of four groups according to the wrist extension of the worse affected wrist: under 30, 30-70, 71-90, and above $90^{\circ}$. Clinical assessment in this regard, in a pilot study, was consistent with results obtained with a goniometer. Clinical assessments were carried out three monthly and the results at entry and after one year of follow-up for $\mathrm{AI}$ and two years for FC, HAQ, and wrist extension were analysed for the purposes of this report.

\section{LABORATORY ASSESSMENT}

At each visit blood was taken for both ESR (Westergren) and C-reactive protein (CRP) (Rocket assay). ${ }^{1 P}$ In addition CIC were measured by the following four assay methods: Clq solid phase using anti-IgG, ${ }^{12} \mathrm{Clq}$ solid phase using protein $\mathrm{A},{ }^{13} \mathrm{Clq}$ PEG,${ }^{4}$ and $2 \%$ PEG. ${ }^{14}$

\section{STATISTICAL METHODS}

The distributions of the results from the four assays of CIC were non-normal and could not be normalised by taking logarithms; thus non-parametric tests were used. Spearman's rank correlation coefficient was used to test for associations between pairs of the different assays at presentation, one year after presentation, and between the changes within each assay during the year. Kendall's coefficient of concordance was used to test for overall concordance between the four assay results. The clinical and other disease measures were treated similarly apart from FC and wrist extension, where patients had in both instances been categorised into one of four increasingly ranked classes. In these instances the $F$ test for linearity was used to test for a relationship of increasing class mean CIC with increase in disease severity as classified by these ranks.

\section{Results}

There were 61 patients for whom complete laboratory and clinical data after one year of follow-up were available. (Raw data are available on request from Dr Alan Silman, Department of Clinical Epidemiology, London Hospital Medical College, London E1.) The other 11 patients, for various technical reasons did not have all the four CIC assays performed at one year of follow-up. There $\stackrel{\mathbb{D}}{\frac{D}{3}}$ were no clinical differences between the patients with and without complete CIC data.

Tables 1 and 2 show the associations between results from the different assays at first visit and one

Table 1 Spearman's rank correlation coefficients for association between the four different assays of immune complexes at first visit

\begin{tabular}{lllll}
\hline & $\begin{array}{l}\text { ClqSP: } \\
\text { anti-IgG }\end{array}$ & $\begin{array}{l}\text { ClqSP: } \\
\text { protein } A\end{array}$ & ClqPEG & $2 \%$ PEG \\
\hline ClqSP:anti-IgG & - & $0 \cdot 311$ & $0 \cdot 152$ & $0 \cdot 207$ \\
ClqSP:protein A & - & 0.328 & $0 \cdot 191$ \\
ClqPEG & & & - & $0 \cdot 691^{* *}$ \\
\hline
\end{tabular}

${ }^{* *} \mathrm{p}<0.01$

Table 2 Spearman's rank correlation coefficients for associations between the four different assays of immune complexes one year after first visit

\begin{tabular}{|c|c|c|c|c|}
\hline & $\begin{array}{l}\text { ClqSP: } \\
\text { anti-IgG }\end{array}$ & $\begin{array}{l}\text { ClqSP: } \\
\text { protein } A\end{array}$ & ClqPEG & $2 \% \quad P E G$ \\
\hline $\begin{array}{l}\text { ClqSP:anti-IgG } \\
\text { ClqSP:protein A } \\
\text { ClqPEG }\end{array}$ & - & $\begin{array}{l}0.569^{* *} \\
-\end{array}$ & $\begin{array}{l}0.401 \\
0 \cdot 312 \\
-\end{array}$ & $\begin{array}{l}0.238 \\
0.273 \text { 으 } \\
0.416^{*}\end{array}$ \\
\hline
\end{tabular}

Table 3 Spearman's rank correlation coefficients for association between changes for the four different assays of $\mathbb{D}$ immune complexes during first year of follow-up

\begin{tabular}{llllll}
\hline & $\begin{array}{l}\text { ClqSP: } \\
\text { anti-IgG }\end{array}$ & $\begin{array}{l}\text { ClqSP: } \\
\text { protein } A\end{array}$ & ClqPEG & $2 \%$ & PEG \\
\hline ClqSP:anti-IgG & - & 0.101 & 0.098 & 0.101 \\
ClqSP:protein A & - & 0.212 & 0.265 \\
ClqPEG & & & - & 0.329 \\
\hline
\end{tabular}

All $\mathrm{p}$ values are non-significant.

Table 4 Spearman's rank correlation coefficients for association between disease activity one year after presentation and the results of the four different assays of immune complexes at presentation

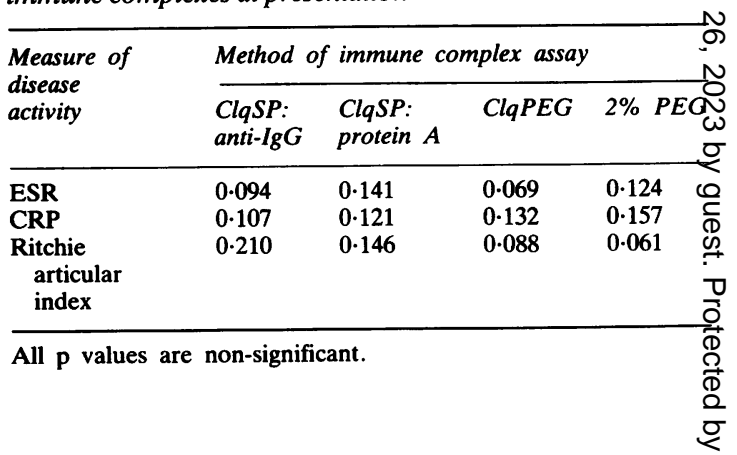


Table 5 Associations between the results for the four measures of immune complex assays at presentation and different measures of disease progression two years after presentation

\begin{tabular}{lllll}
\hline Measure of disease activity & \multicolumn{2}{l}{ Method of immune complex assay } \\
\cline { 2 - 5 } & ClqSP:anti-IgG & ClqSP:protein A & ClqPEG & $2 \%$ PEG \\
\hline 1. Stanford health questionnaire (HAQ) & 0.151 & 0.096 & 0.036 & 0.068 \\
$\quad$ Spearman's rank correlation coefficients) & & & 1.464 \\
2. Steinbocker functional capacity (F test for linearity) & 0.672 & 0.832 & 1.238 \\
3. Wrist extension (F test for linearity) & 0.928 & 0.221 & 0.542 & 0.556
\end{tabular}

All $p$ values are non-significant.

year respectively. The rank correlation coefficients $\left(r_{s}\right)$ were between $0 \cdot 15$ and $0 \cdot 69$. After adjustment for the number of associations tested, only that between ClqPEG and 2\% PEG was significant both at first visit and at one year. In addition there was a significant association at one year between ClqSP:anti IgG and both ClqSP:protein $\mathrm{A}$ and ClqPEG. Kendall's coefficient of concordance, however, was not significant either at first visit or after one year. Conversely the associations between the changes over one year in the different assays were much weaker $\left(r_{\mathrm{s}}\right.$ in range $\left.0 \cdot 10-0 \cdot 33\right)$, with none significant (Table 3 ). Thus changes in any one of the assays did not predict the direction or amount of change in any of the other assays. The individual predictive powers of the four assays at first visit with disease activity at one year are shown in Table 4 . None of the assays were useful in predicting ESR, $\mathrm{CRP}$, or AI at this stage. Similarly the results for the three measures of progression at 2 years (Table 5) show that they cannot be predicted by any of the CIC levels at first visit. There were too few patients with extra-articular manifestations to permit useful analysis.

\section{Discussion}

There was evidence of some relationship between the different assays at the two points of time studied. The correlations at one year were perhaps surprisingly high given that they represent the results from different tests in different laboratories. Comparatively in the WHO study ${ }^{6}$ the same ClqPEG test on the same sample in different laboratories produced an $\mathrm{r}$ value of only 0.44 . Nevertheless in the present study the relationships were neither strong nor consistent. This is perhaps not surprising given that the tests measure different complexes. ${ }^{15}$ The methods all used complement, but the variability between them is such as to produce different results. ${ }^{16}$ Interestingly the two assays utilising a solid phase did not correlate consistently; this may represent different standardisation proce- dures. In addition one assay detected all subclasses of $\mathrm{IgG}$ while the other utilising protein $\mathrm{A}$ would be likely to omit detection of IgG3.

The changes over time showed no consistency between the methods, suggesting that not only do they measure different sized complexes but that the clinical relevance is likely to be very different. Thus the value of CIC in longitudinal studies is doubtful. This was confirmed in the present study, which showed that no individual test was of use in predicting disease activity as measured by ESR, $\mathrm{CRP}$, or AI after one year, nor in predicting disease progression as measured by functional capacity, HAQ, or wrist extension at two years after first visit (three years after disease onset). It may be that further follow-up may highlight a predictive role for CIC, but this remains to be demonstrated. In this series there were no deaths or serious disability by two years, and thus we cannot comment on the possible association of CIC with fulminant disease. Further, as stated earlier, the relationship between CIC and extra-articular disease could not be considered in this study.

We conclude, however, that the variable results from the different assay methods for CIC make any generalised statement about their role in assessing RA impossible. Further, there is no evidence that in early RA any of these four accepted assay methods is of value in predicting later joint disease activity or progression, a clinical role that has been suggested for them. ${ }^{17}$

We acknowledge with gratitude the laboratory assistance of Paul Embling, Lynn Nineham, and Pat Mumford as well as the rheumatologists who referred the patients. This study was financially supported by a project grant from the Arthritis and Rheumatism Council.

\section{References}

1 Kunkel H G, Muller-Eberhard $\mathrm{H} \mathrm{J}$, Fudenberg $\mathrm{H} \mathrm{H}$, et al. Gamma globulin complexes in RA and certain other conditions. J Clin Invest 1961; 40: 117-29.

2 Winchester R J. Agnello V, Kunkel H G. Gamma globulin complexes in synovial fluids of patients with rheumatoid arthritis. Clin Exp Immunol 1970; 6: 689-705. 
3 Zvaiffler N J. Rheumatoid synovitis: an extravascular immune complex disease. Arthritis Rheum 1974; 17: 297-305.

4 Zubler R H, Nydegger V E, Perrin L F, et al. Circulating and intra-articular immune complexes in patients with rheumatoid arthritis. J Clin Invest 1976; 57: 1308-19.

5 Erhardt C L, Mumford P, Maini R N. The association of cryoglobulinaemia with nodules, vasculitis and fibrosing alveolitis in rheumatoid arthritis and their relationship to serum $\mathrm{Clq}$ binding activity and rheumatoid factor. Clin Exp Immunol 1979; 38: 405-13.

6 Lambert P H, Dixon F J, Zubler R H, et al. A collaborative study for the evaluation of 18 methods for detecting immune complex in serum. J Lab Clin Immunol 1978; 1: 1-15.

7 Ropes M W, Bennett G A, Cobb S, et al. Revision of diagnostic criteria for rheumatoid arthritis. Bull Rheum Dis 1958; 9: 175-6.

8 Steinbocker $\mathrm{O}$, Traeger $\mathrm{C} \mathrm{H}$, Bateman $\mathrm{R} \mathrm{C}$. Therapeutic criteria in rheumatoid arthritis. JAMA 1949; 140: 649-62.

9 Ritchie D M, Boyle J A, McInnes J M, et al. Clinical studies with an articular index for the assessment of joint tenderness in patients with rheumatoid artiritis. $Q J$ Med 1968; 37: 393-406.

10 Kirwan J R, Reeback J S. Using a modified Stanford Health
Assessment Questionnaire to assess disability in UK patient with rheumatoid arthritis. Ann Rheum Dis 1983; 42: 219-2200

11 Laurell B. Electroimmunoassay. Scand J Clin Lab Invest 1972 29 (suppl 124): 21-37.

12 Bourke B E, Moss K I, Mumford P, Horsfall A, Maini R N⿳亠口冋 The complement fixing ability to putative circulating immune complexes in rheumatoid arthritis and its relationship to extra-articular disease. Clin Exp Immunol 1982; 48: 726-32

13 Hay F C, Nineham L J, Roitt I M. Routine assay for the detection of immune complexes of known immunoglobulin clas $\$$ using solid phase Clq. Clin Exp Immunol 1976; 24: 396-400

14 Hudson L, Hay F C. Practical immunology. Oxford: Blackwell, 1981: 226

15 Halla J T, Volanakis J E, Schrohenloher R E. Immune complexes in rheumatoid arthritis sera and synovial fluids: a comparison of three methods. Arthritis Rheum 1979; 22\% 440-8.

16 Gupta R C, McDuffie F C, Huston K A, et al. Comparison o three immunoassays for immune complexes in rheumatoid arthritis. Arthritis Rheum 1979; 22: 433-9.

17 Plotz P H. Studies of immune complexes. Arthritis 1982; 25: $1151-5$. 